\title{
A STUDY TO INVESTIGATE THE IMPACT OF SOCIAL RESEARCH TOWARD RESEARCH PRODUCTIVITY
}

\author{
Abdoulaye Kaba \\ Al Ain University, Al Ain, United Arab Emirates \\ Ghaleb A. El Refae \\ Al Ain University, Al Ain, United Arab Emirates \\ Shorouq Eletter \\ Al Ain University, Al Ain, United Arab Emirates \\ Tahira Yasmin \\ Al Ain University, Al Ain, United Arab Emirates
}

\begin{abstract}
The main purpose of this study is to investigate the relationship between demographic diversity and research productivity. The paper attempts to identify the influence of gender diversity, college diversity, and diversity in collaboration on the research productivity of faculty members. The paper is based on data collected from the Deanship of Scientific Research and the Office of Documentation, Al Ain University (AAU). The findings of the study showed significant differences in college diversity. Faculty members of the English instruction colleges dominated the leadership in research productivity. The independent variables appeared to predict $23 \%$ of the variation in research productivity. AAU faculty members should increase internal and external collaborations and network in scientific research. Similarly, AAU also should support and promote research collaboration and networking among faculty members through a comprehensive strategic plan and guidance for internal and external collaborations.
\end{abstract}

Keywords: Research productivity, demographic diversity, faculty members, Al Ain University, United Arab Emirates

DOI: http://dx.doi.org/10.15549/jeecar.v8i4.676

\section{INTRODUCTION}

The rate at which scientific output is generated - scientific productivity - is essential for the creation, sharing, and transfer of knowledge. It is employed as a performance metric at both individual and institutional levels. For academic institutions, it gives them a competitive advantage, while for individual scholars, it enables them to engage in self-marketing, acquire a new job, and obtain a promotion.

Specifically, scientific productivity is measured by the number of scientific publications an 
academic has to their name (Abramo \& D'Angelo, 2014). Publications in the research field are types of technical and scientific capital generated by researchers that comprise resources and practical skills along with links to professional networks (Bozeman \& Corley, 2004). Scientific productivity plays an important role in stimulating both economic and social growth (Szuflita-Zurawska, et al., 2020).

The evaluation of research is a vital activity, the aim of which is to ensure that research continues to improve (Abramo et al., 2019b). As pointed by Krueger and Megits (2021), the quality of research has an impact on the reputation of a faculty member, college, and academic institution. To measure the impact (Abramo \& D'Angelo, 2014) or quality of research (Waltman, 2016), citations are widely employed as performance indicators (Aksnes et al., 2019). The diverse nature of research is ensured when scientific research involves collaboration between multi-skilled researchers with diverse demographic, cognitive, and experiential backgrounds. This enables scholars from a broad ambit of disciplines to participate in large scale projects, develop their aptitudes, and enhance both the quantity and quality of research outputs (Abramo et al., 2019a). This serves to promote scientific productivity (Ductor, 2015). Among the many reasons why researchers choose to work with scholars from other countries is to acquire scientific recognition, access research funds, and enhance their status as academics (Kwiek, 2020, El Refae, Belarbi, Abu Rashed, 2017)

This study aims to explore the relationship between research productivity and demographic diversity. To achieve this, we obtained all the research reports available at the AAU office for documentation. AAU has two campuses, the main campus in Al Ain City, and a branch campus in Abu Dhabi. To analyze the data, a descriptive analysis, t-test, and regression analysis was performed.

The structure of this paper is as follows, Section 1 is an introduction; Section 2 reviews the relevant literature; Section 3 outlines the methodology and data that are used, research questions, and research hypotheses; Section 4 presents findings; Section 5 discussion; and Section 6 ties the findings together in an overall conclusion.

\section{LITERATURE REVIEW}

The term diversity may refer to demographic diversity, experiential diversity, and cognitive diversity. Demographic diversity is about the attributes and characteristics that we carry with us, such as gender, age, race, and academic major. Experiential diversity is about personal experiences that shape our emotions and feelings, including hobbies and abilities, while cognitive diversity is about different methods and approaches we use in thinking and problem solving (de Anca \& Aragon, 2018). This section presents previous studies that have investigated the issue of demographic diversity with research productivity and research impact.

Prior studies have used gender (Leahey, 2006; Tower, Plummer, \& Ridgewell, 2007; Bell \& Fong, 2021), academic major or specialization ( $\mathrm{Hu} \&$ Gill, 2000; Cheng et al., 2003), and research collaboration (Autry \& Griffis, 2005; Aldieri, Guida, Kotsemir, \& Vinci, 2019; Choi \& Oh, 2020) as demographic diversity variables in investigating research productivity and research impact. A study by Kotrlik, Bartlett, Higgins, and Williams (2002) revealed that gender did not explain faculty productivity in research. Similarly, Tower, Plummer, and Ridgewell (2007) reported no significant difference between men and women in research productivity and research impact. On the other hand, research reports by Leahey (2006), Abramo, D’Angelo, and Caprasecca (2009), and also by Hedjazi and Behravan (2011), found gender diversity a significant predictor of research productivity among faculty members.

An international comparison study conducted by Aiston and Jung (2015) explored gender diversity and research productivity using Changing Academic Profession (CAP) data. The authors found that women faculty members in Japan published less as compared to men. They also reported a more noticeable gap between senior male and female academics as compared to junior academics in Germany, Finland, and the USA. A similar study by Koseoglu, King, and Rahimi (2019) reported significant gender diversity of research productivity in the USA, the UK, Canada and France. Recently, Sá, Cowley, Martinez, Kachynska, and Sabzalieva (2020) reported gender diversity in research productivity in the USA, Canada, and South 
Africa. The authors found that men published $16 \%$ more papers than women and were cited $68 \%$ more frequently than women.

Researchers have also explored the impact of the COVID-19 pandemic on faculty research productivity (Cui, Ding, \& Zhu, 2020; Bell \& Fong, 2021). A research report by Cui, Ding, and Zhu (2020) found that, after 10 weeks of lockdown in the United States, research productivity increased by 35\%; female academics' productivity, however, dropped by $13.2 \%$ as compared to that of male academics. Similarly, Bell and Fong (2021) investigated gender diversity in submitting research papers to the American Journal of Public Health before and during the COVID-19 pandemic. The findings of the study indicated that the submission rates were higher during the pandemic as compared to before the pandemic. However, the number of submissions increased by $23.8 \%$ for men but only $7.9 \%$ for women. Women authored $29.4 \%$ of COVID-19-related articles.

Like gender, academic major or specialization have been explored in light of faculty research productivity (Benbasat \& Weber, 1996) and research impact (Long, Barnett, White, \& Bowers, 1998). To understand the research productivity of faculty members majoring in information systems (IS), Hu and Gill (2000) used a life-cycle model of academic research and previous studies on data collected through a national survey. Results of the study revealed no significant relationship between academic major and the research productivity of faculty members. For marketing, Cheng et al. (2003) used 20 marketing journals to examine the research productivity of faculty members. Findings of the study showed that the research productivity of top Asia-Pacific marketing faculty members is comparable with that of American counterparts. Similar studies have been conducted on logistics research (Autry \& Griffis, 2005; Cantor, Bolumole, Coleman, \& Frankel, 2010), sociology and linguistics (Leahey, 2006), operations management (Smith, Fox, Park, \& Lee, 2008), agriculture (Hedjazi \& Behravan, 2011), and accounting (Wills, Ridley, \& Mitev, 2013).

Collaboration in research is another important demographic variable for understanding faculty research productivity (Reich \& Reich, 2006; Lewis, Ross, \& Holden, 2012) and reach impact
(Abramo, D’Angelo, \& Di Costa, 2009). As stated by Bozeman, Fay, and Slade (2013), collaboration has become the norm in scientific research. According to Huang (2014), collaboration is required in research to address complex research issues, to learn and improve research productivity, to reduce research cost, and to improve intellectual companionship. A case study conducted by Ceballos, Jr., Galeano, Juarez and Cantu-Ortiz (2017) at a Mexican university reported the impact of collaboration on research productivity and the research impact of faculty members. The authors believe that knowledge management increases research collaboration and thereby increases research productivity and research impact. An investigation of logistics research collaboration in Asia by Wu, Goh, Yuan, and Huang (2017) found collaboration did not exceed three authors. Besides, the extent of cross-sector collaboration was low at only $10 \%$, while $70 \%$ of the research collaboration focused on Northeast Asia. Eduan and Yuanqun (2019) used bibliometric analysis to examine research collaboration between China and African countries. Results of the study indicated that the partnership is growing progressively. However, a few of the African countries were more engaged in the collaboration than the others. Other studies have reported the impact of collaboration on research productivity and research impact in Italy (Aldieri et al.,2019), and other countries (Choi \& Oh 2020).

The review of literature has presented important studies that used demographic variables to investigate research productivity and the research impact of faculty members. As discussed in this section, prior studies have reported conflicting results about the relationship between demographic variables and research productivity or research impact. The current study is attempting to examine the impact of demographic diversity, specifically gender, college, academic specialization, and research collaboration on research productivity and research impact. The findings of the study could contribute to the concept of diversity in scientific research.

\section{METHODOLOGY}

The current study is based on data collected from the annual scientific research reports available at 
the Deanship of Scientific Research and the Office of Documentation, Al Ain University (AAU). The study was conducted using the mixed approach method. The mixed approach method is widely used in bibliometric studies (Eduan \& Yuanqun, 2019). The study used a qualitative approach for data collection and a quantitative approach in analyzing the data.

The study is based on two concepts, (1) demographic diversity and (2) research productivity (Table 1). The concept of demographic diversity refers to the personal characteristics of faculty members in this study. The characteristics are gender, college, and level of collaboration. These three characteristics are used as independent variables in this study. On the other hand, the concept of research productivity refers to the number of documents produced by a faculty member during his or her work with AAU.

Table 1: The study variables and indicators

\begin{tabular}{|c|l|l|}
\hline \multirow{2}{*}{ Concept } & \multicolumn{1}{|c|}{ Independent Variable } & \multicolumn{1}{|c|}{ Indicator } \\
\hline \multirow{2}{*}{ Demographic diversity } & Gender & $\begin{array}{l}\text { Male } \\
\text { Female }\end{array}$ \\
\cline { 2 - 3 } & College & $\begin{array}{l}\text { English Instruction College } \\
\text { Arabic Instruction College }\end{array}$ \\
\cline { 2 - 3 } & Collaboration & $\begin{array}{l}\text { High (number of coauthored papers } \\
\text { above 5) } \\
\text { Low (number of coauthored papers } \\
\text { below 5) }\end{array}$ \\
\hline Concept & Dependent Variable & \multicolumn{1}{c|}{ Indicator } \\
\hline Research productivity & Publications & Number of publications \\
\hline
\end{tabular}

The collected data were analyzed using Microsoft Excel and the Statistical Package for the Social Sciences (SPSS). The analysis was guided by research questions and hypotheses stated in the study by generating frequency distributions, percentages, correlations, and regression statistics.

\section{RESEARCH QUESTIONS}

1. Is gender diversity-related to research productivity?

2. Is College diversity related to research productivity?

3. Is collaboration related to productivity?

\section{RESEARCH HYPOTHESES}

H1. Diversity in gender is not related to research productivity.

$\mathrm{H} 2$. College diversity is not related to research productivity.
H3. Collaboration is not related to research productivity.

\section{FINDINGS}

This section discusses the findings of the study. It focuses on the findings related to research productivity, leaders and drivers of research productivity, demographic diversity differences in research productivity, and identifying relationships among the research variables.

\section{RESEARCH PRODUCTIVITY}

Figure 1 presents the growth of AAU research from 2005 to 2019. Based on the number of documents identified in this study, AAU recorded 1194 documents in 15 years, from 2005 to 2019. This number indicates an average of 79.6 papers per year. However, the highest number of research publications $(\mathrm{n}=256,21.44 \%)$ were published in 2019, followed by 2017 ( $n=217$, $18.17 \%)$, and 2018 ( $n=191,15.99 \%)$. 
Meanwhile, by looking at the types of documents, findings of the study (Figure 2) indicate that the top three types of documents published by AAU faculty members are articles
( $n=889,74.45 \%)$, followed by conference papers $(n=283,23.70 \%)$, and books $(n=22,1.84 \%)$.

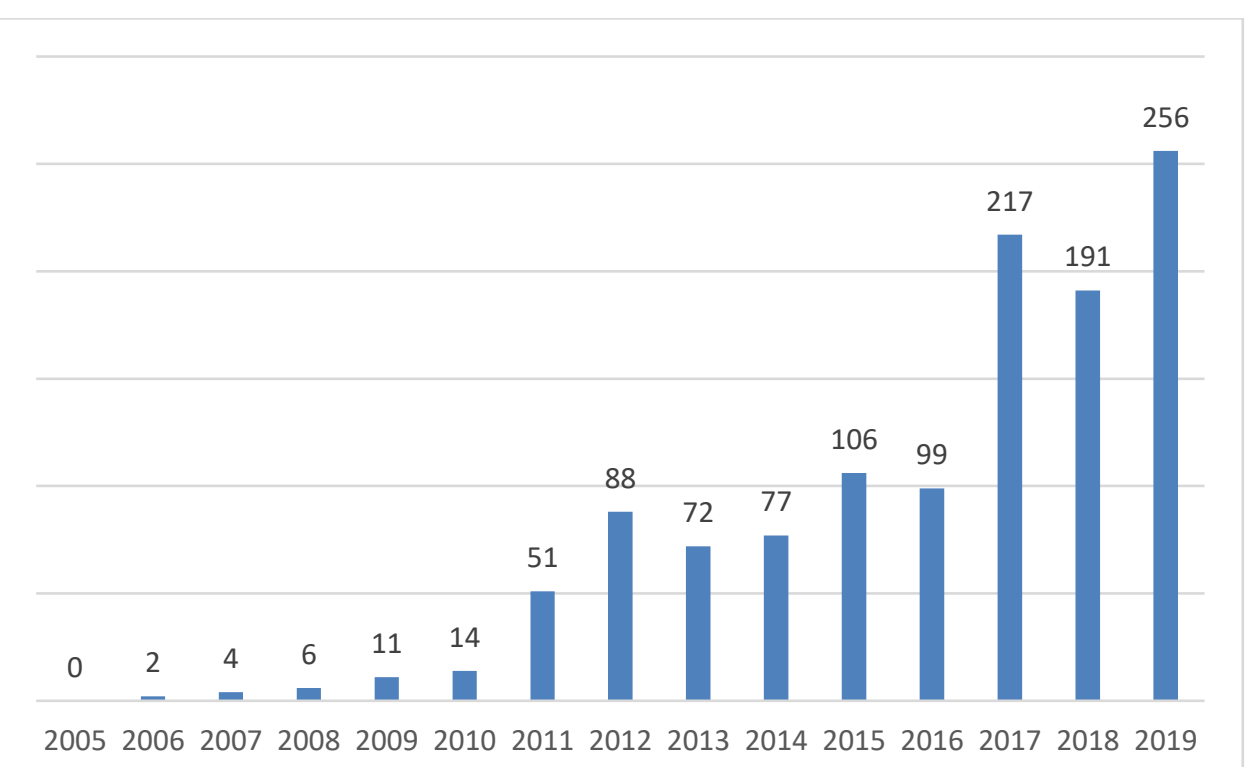

Figure 1: Research productivity per year

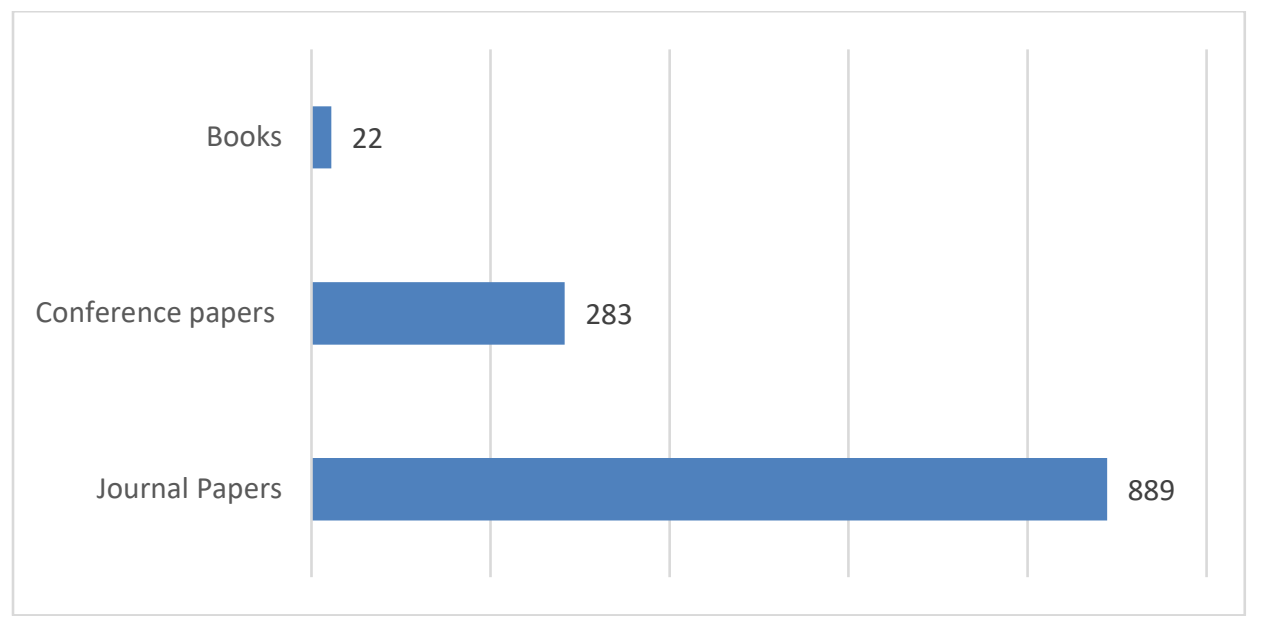

Figure 2: Document types

\section{LEADERS AND DRIVERS OF RESEARCH PRODUCTIVITY}

In this section, we discuss leaders and drivers of research productivity and research impact at AAU by identifying the top ten authors and contributors and the top ten collaborators. The study identified 138 faculty members who contributed to the research productivity at AAU.
Of the 138 contributors identified, 38 names are considered top productive faculty members, 35 men and only 3 women. The top ten authors contributed 306 out of 1194 documents, indicating a $25.62 \%$ contribution to the total documents under the study (Table 2 ).

Regarding leaders and drivers in collaboration and co-authorship, the analysis of data indicated that the faculty members produced 210 
collaborated papers with other authors. Moreover, male faculty members collaborated on 178 papers compared to 32 for female faculty members (Table 3 ).

Table 2: Top ten contributors, 2005-2016

\begin{tabular}{|c|c|c|c|c|}
\hline Rank & $\begin{array}{c}\text { Member } \\
\text { of Rank }\end{array}$ & $\mathbf{M}$ & $\mathbf{F}$ & $\begin{array}{c}\text { Single } \\
\text { Contributio } \\
\mathbf{n}\end{array}$ \\
\hline 1 & 1 & 1 & 0 & 15 \\
\hline 2 & 2 & 2 & 0 & 14 \\
\hline 3 & 2 & 2 & 0 & 12 \\
\hline 4 & 1 & 1 & 0 & 11 \\
\hline 5 & 1 & 1 & 0 & 10 \\
\hline 6 & 4 & 4 & 0 & 9 \\
\hline 7 & 5 & 4 & 1 & 8 \\
\hline 8 & 6 & 5 & 1 & 7 \\
\hline 9 & 8 & 7 & 1 & 6 \\
\hline 10 & 8 & 8 & 0 & 5 \\
\hline
\end{tabular}

\section{DEMOGRAPHIC DIVERSITY DIFFERENCES IN RESEARCH PRODUCTIVITY}

In this study, demographic diversity variables are gender, college, and collaboration. For gender diversity, the findings indicate that male faculty members published more papers $(\mathrm{n}=978$, $81.90 \%)$ than female faculty members $(n=216$, $18.09 \%$ ). For college diversity, faculty members affiliated with English instruction colleges published more research papers ( $n=934,78.22 \%)$ than faculty members of Arabic instruction colleges $(n=260,21.77 \%)$. Likewise, faculty members with a high level of collaboration published more research papers $(n=898,75.20 \%)$
Table 3: Top ten collaborators, 2005-2016

\begin{tabular}{|c|c|c|c|c|}
\hline Rank & $\begin{array}{c}\text { Member } \\
\text { of Rank }\end{array}$ & $\mathbf{M}$ & $\mathbf{F}$ & Collaboration \\
\hline 1 & 2 & 2 & 0 & 13 \\
\hline 2 & 2 & 1 & 1 & 12 \\
\hline 3 & 3 & 2 & 1 & 10 \\
\hline 4 & 3 & 3 & 0 & 9 \\
\hline 5 & 1 & 1 & 0 & 7 \\
\hline 6 & 2 & 1 & 1 & 6 \\
\hline 7 & 4 & 4 & 0 & 5 \\
\hline 8 & 7 & 6 & 1 & 4 \\
\hline 9 & 6 & 6 & 0 & 3 \\
\hline 10 & 9 & 9 & 0 & 2 \\
\hline
\end{tabular}

as compared to faculty members with a low level of collaboration ( $n=296,24.79 \%$ ).

On the other hand, an independent t-test analysis illustrated in Table 4, indicates that the differences in gender diversity among faculty members are statistically significant ( $\mathrm{t}$-value $=$ 2.053, p-value=0.042). Similarly, the analysis reveals significant differences in collaboration with other researchers $(t$-value $=5.910$, $p$-value $=$ 0.000 ). Interestingly, the findings of the study showed statistically no significant difference in college diversity (with respect to research productivity $\mathrm{t}-$ value $=0.061, \mathrm{p}$-value $=0.952$ ).

Table 4: Demographic Diversity Differences in research productivity

\begin{tabular}{|c|c|c|c|c|c|c|}
\hline Variable & Indicator & Productivity (\%) & Mean & SD & t-value & p-value \\
\hline \multirow{2}{*}{ Gender } & Male & $978(81.90)$ & 3.68 & 3.434 & \multirow{2}{*}{2.053} & \multirow{2}{*}{0.042} \\
\hline & Female & $216(18.09)$ & 2.21 & 2.378 & & \\
\hline \multirow{2}{*}{ College } & English & $934(78.22)$ & 3.36 & 3.549 & \multirow{2}{*}{0.061} & \multirow{2}{*}{0.952} \\
\hline & Arabic & $260(21.77)$ & 3.32 & 3.051 & & \\
\hline \multirow{2}{*}{ Collaboration } & High & $898(75.20)$ & 7.17 & 3.839 & \multirow{2}{*}{5.910} & \multirow{2}{*}{0.000} \\
\hline & Low & $296(24.79)$ & 2.77 & 2.795 & & \\
\hline
\end{tabular}




\section{IDENTIFYING THE RELATIONSHIP}

The current study investigates the relationship of demographic diversity to research productivity. The concept of demographic diversity is measured using three independent demographic diversity variables. These independent variables are gender, colleges, and collaboration or co-authorship. On the other hand, the number of publications is a dependent variable used to measure the concept of research productivity.

Table 5 illustrates the results of Spearman's rho correlation analysis. This non-parametric test was preferred because an early normality test indicated that the data are not normally distributed, particularly in research productivity. The correlation analysis shows a statistically positive significant relationship between college diversity or collaboration diversity and research productivity ( $r s=0.179,0.521$ ), respectively. The findings provide answers to the second and third research questions, and at the same time, reject the second and third stated hypotheses in this study.

On the other hand, gender diversity indicates a statistically negative significant relationship with research productivity ( $\mathrm{rs}=-0.181$ ), respectively. The result provides an answer to the first research question but rejects the first hypothesis (H1) of the study.

Table 5: Spearman's rho correlation analysis

\begin{tabular}{|l|c|c|c|c|}
\hline \multicolumn{1}{|c|}{ Variable } & 1 & 2 & 3 & 4 \\
\hline 1. Gender diversity & 1 & & & \\
\hline 2. College diversity & -0.006 & 1 & & \\
\hline 3. Collaboration & -0.065 & $-0.176^{*}$ & 1 & \\
\hline 4. Research productivity & $-0.181^{*}$ & $0.179^{*}$ & $0.521^{* *}$ & 1 \\
\hline
\end{tabular}

**. Correlation is significant at the 0.01 level (2-tailed). *. Correlation is significant at the 0.05 level (2tailed).

Based on the above results, we performed a linear regression analysis to find out the effect of gender diversity, college diversity, and collaboration diversity on research productivity. The regression tests are based on the partial least squares' structural equation modelling (PLSSEM) as follows:

$$
\begin{gathered}
\mathrm{Y} 1=\beta_{0}+\beta_{1} \text { Gender }+\beta_{2} \text { College }+ \\
\beta_{3} \text { Collaboration }+\varepsilon
\end{gathered}
$$

\begin{tabular}{|c|c|}
\hline Variable & Definition \\
\hline Y1 & $\begin{array}{l}\text { = Research productivity } \\
\text { (number of documents } \\
\text { reported for faculty } \\
\text { members) }\end{array}$ \\
\hline Gender & $\begin{array}{l}=1 \text { if respondent is male, } 0 \text { if } \\
\text { female }\end{array}$ \\
\hline College & $\begin{array}{l}=1 \text { if faculty member is from } \\
\text { English instruction college, } 0 \\
\text { if Arabic }\end{array}$ \\
\hline Collaboration & $\begin{array}{l}=\text { number of coauthors or } \\
\text { contributors }\end{array}$ \\
\hline$\varepsilon$ & $=$ errors \\
\hline
\end{tabular}

Table 6: Definitions of variables
As illustrated in Table 6, the results of the regression analysis support the suggested model of the study by demonstrating statistically the significant effect of gender diversity, college diversity, and collaboration on the research productivity $\left(\mathrm{R}^{2}=0.235, \mathrm{~F}=13.687, \mathrm{p}\right.$-value $<.05)$.

Table 7: Coefficient of variable

\begin{tabular}{|c|c|c|}
\hline \multirow{2}{*}{ Variable } & \multicolumn{2}{|c|}{ Research Productivity } \\
\cline { 2 - 3 } & Coefficient & p-value \\
\hline \multicolumn{3}{|c|}{ (Constant) } \\
\hline Gender & -0.164 & 0.032 \\
\hline College & 0.074 & 0.334 \\
\hline Collaboration & -0.457 & 0.000 \\
\hline
\end{tabular}

Note: $\mathrm{R}^{2}=0.235, \mathrm{~F}=13.687$, $\mathrm{p}$-value $=0.000$

The results demonstrate that the three independent variables together (gender, college, and collaboration) explain at least $23 \%$ of the variance in research productivity among faculty members. 


\section{DISCUSSION}

This research was conducted to explore research diversity at AAU. The paper investigated the relationship between the research productivity and demographic diversity of faculty member. The findings of the study identified 1194 documents produced by AAU faculty members from 2005-2019, with an average of 79.60 papers per year, approximately an average of 8.65 documents per faculty member.

Table 8: Summary

\begin{tabular}{|l|c|}
\hline \multicolumn{1}{|c|}{ Item } & Number \\
\hline Total documents & 1194 \\
\hline $\begin{array}{l}\text { Average documents per year } \\
\text { (2005-2019) }\end{array}$ & 79.60 \\
\hline $\begin{array}{l}\text { Average documents per } \\
\text { faculty member }\end{array}$ & 8.65 \\
\hline
\end{tabular}

The last three years, 2019, 2018, and 2017, appear to be the most productive period, which reflects the commitment of AAU management to improve research productivity and the research output of faculty members. Before 2017, AAU faculty members could achieve hardly more than 100 documents per year. This scenario changed in 2017 with the production of 217 documents, followed by 191 documents in 2018, and 256 documents in 2019.

The findings of the study reveal that, despite efforts and time needed to publish an article in scholarly journals, faculty members are more likely to publish journal articles than the other types of publications. This finding supports the recent study reported by Liyanagunawardena, Adams, and Williams (2021). The motive for publishing more journal articles than other types of publications could be related to academic promotion, research impact, academic reputation, and research funds, as well as research incentives.

The results of the study show that faculty members of the English instruction colleges, namely the College of Engineering, Pharmacy, and Business, dominated the leadership in productivity and collaboration. The differences are statically significant at the college level. This indicates that the faculty members of the three colleges are more active in research than the faculty members of the Arabic instruction colleges. At the same time, it indicates challenges faced by the faculty members from the Arabic instruction colleges. The challenges include the time needed to publish a paper in an Arabic journal and publishing research papers in English. These challenges could be essential factors contributing negatively to the research productivity of faculty members from Arabic instruction colleges.

Results of the study have provided answers to research questions and determined the status of the stated hypotheses (Table 8). Interestingly, gender demonstrated a negative relationship with research productivity.

Table 9: Status of the tested hypotheses

\begin{tabular}{|c|l|l|l|}
\hline Code & \multicolumn{1}{|c|}{ Hypothesis } & Test result & Status \\
\hline H1 & $\begin{array}{l}\text { Diversity in gender is not } \\
\text { related to research productivity. }\end{array}$ & Not related & Not supported \\
\hline H2 & $\begin{array}{l}\text { College diversity is not related } \\
\text { to research productivity. }\end{array}$ & Negative relation & Not supported \\
\hline H3 & $\begin{array}{l}\text { Diversity in collaboration is not } \\
\text { related to research productivity. }\end{array}$ & Positive relation & \\
\hline
\end{tabular}

Our finding contradicts the studies reported by Williams (2002), Plummer, and Ridgewell (2007). However, it supports research reports that found gender diversity a significant predictor of research productivity among faculty members (Leahey, 2006; Abramo, D’Angelo, \& Caprasecca, 2009; Hedjazi \& Behravan, 2011).

The most striking results are identified in research collaboration. The findings of the study indicate a statistically positive significant relationship between collaboration and research 
productivity. The regression analysis revealed that the study model explains $23 \%$ of the variance in research productivity. This indicates that the three variables can predict the level of research productivity among faculty members. These findings support the previous studies (Aldieri et al.,2019; Choi \& Oh 2020) that reported the impact of collaboration on faculty research productivity.

\section{CONCLUSION}

Diversity in research is highly demonstrated by AAU faculty members. They are aware of the importance of research diversity in research productivity. Diversity in research collaboration, particularly, has a significant impact on research productivity and research impact. Therefore, AAU faculty members should increase internal and external collaborations and networks in scientific research. Similarly, AAU also should support faculty members in research collaboration and networking through a comprehensive strategic plan and guidance for internal and external collaborations. Perhaps a special research fund and incentive could be essential factors to implement and realize the strategic plan.

This is a case study that targeted faculty research productivity at AAU with gender, college, and collaboration as demographic diversity variables. The annual scientific reports available at the Deanship of Scientific Research and the Office of Documentation were used to identify and collect the needed data and information. Therefore, the findings of the study may not be generalized to similar situations. Besides, the results of the study could be different if bibliographic data are collected from multiple sources such as the Scopus database, Web of Science, Google Scholar, and ResearchGate. Therefore, future studies may extend this topic to include more bibliographic sources and more diverse variables research and science research.

\section{REFERENCES}

Abramo, G., D’Angelo, C. A., \& Caprasecca, A. (2009). Gender differences in research productivity: A bibliometric analysis of the Italian academic system. Scientometrics,
79(3), 517-539.

https://doi.org/10.1007/s11192-007-2046-8

Abramo, G., D'Angelo, C. A., \& Di Costa, F. (2009). Research collaboration and productivity: Is there correlation? Higher Education, 57(2), 155-171. https://doi.org/10.1007/s10734008-9139-z

Abramo, G., D’Angelo, C. A., \& Di Costa, F. (2019). A gender analysis of top scientists' collaboration behavior: evidence from Italy. Scientometrics, 120(2), 405-418.

Abramo, G., \& D’Angelo, C. A. (2014). How do you define and measure research productivity?. Scientometrics, 101(2), 11291144.

Abramo, G., D’Angelo, C. A., \& Felici, G. (2019b). Predicting publication long-term impact through a combination of early citations and journal impact factor. Journal of Informetrics, 13(1), 32-49.

Aiston, S. J., \& Jung, J. (2015). Women academics and research productivity: an international comparison. Gender and Education, 27(3), 205-220. https://doi.org/10.1080/09540253.2015.102 4617

Aldieri, L., Guida, G., Kotsemir, M., \& Vinci, C. P. (2019). An investigation of impact of research collaboration on academic performance in Italy. Quality and Quantity (Vol. 53). Springer Netherlands. https://doi.org/10.1007/s11135-019-008531

Aksnes, D. W., Langfeldt, L., \& Wouters, P. (2019). Citations, citation indicators, and research quality: An overview of basic concepts and theories. Sage Open, 9(1), 215

Autry, C. W., \& Griffis, S. E. (2005). A social anthropology of logistics research: Exploring productivity and collaboration in an emerging science. Transportation Journal, 44(4), 27-43.

Bell, M. L., \& Fong, K. C. (2021). Gender differences in first and corresponding authorship in public health research submissions during the COVID-19 pandemic. American Journal of Public Health, 111(1), 159-163. https://doi.org/10.2105/AJPH.2020.305975 
Benbasat, I., \& Weber, R. (1996). Research commentary: rethinking diversity in information systems research. Information Systems Research, 7(4), 389-399.

Bozeman, B., \& Corley, E. (2004). Scientists' collaboration strategies: implications for scientific and technical human capital. Research policy, 33(4), 599-616.

Bozeman, B., Fay, D., \& Slade, C. P. (2013). Research collaboration in universities and academic entrepreneurship: The-state-ofthe-art. Journal of Technology Transfer (Vol. 38). https://doi.org/10.1007/s10961-0129281-8

Ductor, L. (2015). Does co-authorship lead to higher academic productivity?. Oxford Bulletin of Economics and Statistics, 77(3), 385-407.

Cantor, D. E., Bolumole, Y., Coleman, B. J., \& Frankel, R. (2010). An examination of trends and impact of authorship collaboration in Logistics Research. Journal of Business Logistics, 31(1), 197-215. https://doi.org/10.1002/j.21581592.2010.tb00135.X

Ceballos, H. G., Jr., J. F., Galeano, N., Juarez, E., \& Cantu-Ortiz, F. J. (2017). Impelling research productivity and impact through collaboration : a scientometric case study of knowledge management. Knowledge Management Research \& Practice, (15), 346355. https://doi.org/10.1057/s41275-0170064-8

Cheng, L. T. W., Chan, K. C., \& Chan, R. Y. K. (2003). Publications in major marketing journals: an analysis of research productivity of Asia-Pacific universities. Journal of Marketing Education, 25(2), 163176. https://doi.org/10.1177/0273475300222004

Choi, H. do, \& Oh, D. hyun. (2020). The importance of research teams with diverse backgrounds: Research collaboration in the Journal of Productivity Analysis. Journal of Productivity Analysis, 53(1), 5-19. https://doi.org/10.1007/s11123-019-00567-4

Cui, R., Ding, H., \& Zhu, F. (2020). Gender inequality in research productivity during the COVID-19 pandemic. Social Science
Research Network, Preprint(June), 1-25. https://doi.org/10.2139/ssrn.3623492

de Anca, C., \& Aragon, S. (2018). The 3 types of diversity that shape our identities. Harvard Business Review, 3-7. Retrieved from https://hbr.org/2018/05/the-3-types-ofdiversity-that-shape-our-identities

Eduan, W., \& Yuanqun, J. (2019). Patterns of the China-Africa research collaborations from 2006 to 2016: a bibliometric analysis. Higher Education, 77(6), 979-994. https://doi.org/10.1007/s10734-018-0314-6

El Refae, G. A., Belarbi, A. K. Abu Rashed, J. A. (2017). University governance: risk management approach. AAU Journal of Business and Law, 1(1), 7-17.

Hedjazi, Y., \& Behravan, J. (2011). Study of factors influencing research productivity of agriculture faculty members in Iran. Higher Education, 62(5), 635-647. https://doi.org/10.1007/s10734-011-9410-6

Hu, Q., \& Gill, T. G. (2000). IS Faculty Research Productivity: Influential Factors and Implications. Information Resources Management Journal (IRMJ), 13(2), 15-25. https://doi.org/10.4018/irmj.2000040102

Huang, J. S. (2014). Building research collaboration networks: an Interpersonal perspective for Research Capacity Building. Journal of Research Administration, 45(2), 89-112. Retrieved from http://search.ebscohost.com/login.aspx?dire $c t=$ true \&db=bth\&AN=110547921\&site=ehos t-live

Koseoglu, M. A., King, B., \& Rahimi, R. (2019). Gender disparities and positioning in collaborative hospitality and tourism research. International Journal of Contemporary Hospitality Management, 32(2), 535-559. https://doi.org/10.1108/IJCHM-09-20180747

Krueger, T. M. \& Megits, N. (2021). The impact of economics and financial research published in Central and Eastern Europe. Journal of Eastern European and Cntral Asian Research. 8(1), 1-17.

Kotrlik, J. W., Bartlett, II, J. E., Higgins, C. C., \& Williams, H. A. (2002). Factors associated with research Productivity of agricultural 
education faculty. Journal of Agricultural Education, 43(3), 1-10. https://doi.org/10.5032/jae.2002.03001

Kwiek, M. (2020). What large-scale publication and citation data tell us about international research collaboration in Europe: changing national patterns in global contexts. Studies in Higher Education, 1-21.

Leahey, E. (2006). Gender differences in productivity: Research specialization as a missing link. Gender and Society, 20(6), 754-780. https://doi.org/10.1177/0891243206293030

Lewis, J. M., Ross, S., \& Holden, T. (2012). The how and why of academic collaboration: Disciplinary differences and policy implications. Higher Education, 64(5), 693708. https://doi.org/10.1007/s10734-0129521-8

Liyanagunawardena, T. R., Adams, A. A., \& Williams, S. A. (2021). MOOCs : a systematic study of the published Literature 20082012. Internaaional Review of Research in Open and Distributed Learning, 14(3), 202227.

Long, R. G., Barnett, T., White, M. C., \& Bowers, W. P. (1998). Research productivity of graduates in management: Effects of academic origin and academic affiliation. Academy of Management Journal, 41(6), 704-714. https://doi.org/10.2307/256966

Reich, S. M., \& Reich, J. A. (2006). Cultural competence in interdisciplinary collaborations: a method for respecting diversity in research partnerships. AAmerican Journal of Community Psychology, 38(1-2), 51-62. https://doi.org/10.1007/s10464-006-9064-1

Sá, C., Cowley, S., Martinez, M., Kachynska, N., \& Sabzalieva, E. (2020). Gender gaps in research productivity and recognition among elite sicentists in the U.S., Canada, and South Africa. PLOS One, 15(10), e0240903.

Smith, J. S., Fox, G. L., Park, S. H., \& Lee, L. (2008). Institutional antecedents to research productivity in operations: The US perspective. International Journal of Operations and Production Management, 28(1), 7-26. https://doi.org/10.1108/01443570810841086
Szuflita-Zurawska, M., Basinska, B. A., \& Krzysztof, L. E. J. A. (2020). Barriers to and facilitators of scientific productivity: A case study from Polish technical university.

Tower, G., Plummer, J., \& Ridgewell, B. (2007). A Multidisciplinary Study Of Gender-Based Research Productivity In The Worlds Best Journals. Journal of Diversity Management (JDM), 2(4), 23-32. https://doi.org/10.19030/jdm.v2i4.5020

Waltman, L. (2016). A review of the literature on citation impact indicators. Journal of informetrics, 10(2), 365-391.

Wills, D., Ridley, G., \& Mitev, H. (2013). Research productivity of accounting academics in changing and challenging times. Journal of Accounting \& Organizational Change, 9(1), 425. https://doi.org/10.1108/18325911311307186

Wu, Y. C., Goh, M., Yuan, C. H., \& Huang, S. H. (2017). Logistics management research collaboration in Asia. International Journal of Logistics Management, 28(1), 206-223. https://doi.org/10.1108/IJLM-09-2013-0104

\section{ABOUT THE AUTHORS}

Abdoulaye Kaba, email: kaba_abdoulaye@yahoo.com

Dr. Abdoulaye Kaba is Assistant Professor and Library Director, College of Education, Humanities and Social Sciences, Al Ain University, Al Ain, United Arab Emirates.

Prof. Ghaleb A. El Refae is Professor, College of Business, Al Ain University, Al Ain, United Arab Emirates.

Dr. Shorouq Eletter is Associate Professor, College of Business, Al Ain University, Al Ain, United Arab Emirates.

Dr. Tahira Yasmin is Assistant Professor, College of Business, Al Ain University, Al Ain, United Arab Emirates. 